\title{
Research Article \\ DIVERGENCE STUDIES FOR YIELD AND GALL MIDGE TOLERANCE IN RICE (Oryza sativa L.)
}

\author{
SRINIVAS B. ${ }^{*}$, CHANDRAMOHAN Y., THIPPESWAMY S., PADMAJA D. AND OMPRAKASH S. \\ Rice Research Scheme, Regional Agricultural Research Station, Professor Jayashankar Telangana State Agricultural University, Polasa, Jagtial, Telangana, 505529 \\ *Corresponding Author: Email - srinu.bdd@gmail.com
}

Received: April 21, 2018; Revised: April 26, 2018; Accepted: April 27, 2018; Published: April 30, 2018

\begin{abstract}
Regional Agricultural Research Station, Polasa, Jagtial, Telangana during Kharif, 2014 revealed presence of ample amount of variability among the genotypes studied. Clustering pattern revealed no correlation between grouping pattern of genotypes and their origin. Highest inter cluster distance was observed between cluster IV and VIII (17.59) followed by II and VIII (15.91), V and VIII (15.66) and I and VIII (15.05) and genotypes from these cluster could be used as parents for obtaining desirable segregants. Genotypes from clusters I, II and IV could yield early maturity genotypes and JGL 21800 and JGL 11470 are good source for developing gall midge resistant lines. Segregants with good head rice recovery could be possible by using genotypes from clusters III, IV and $\mathrm{VI}$ as parents. Effective bearing tillers per plant which is an important yield contributing character contributed maximum (27.2\%) towards total divergence, hence present experiment material could be used to improve this trait in desirable direction.
\end{abstract}

Key words- Rice, gall midge, genetic divergence

Citation: Srinivas B., et al., (2018) Divergence Studies for Yield and Gall Midge Tolerance in Rice (Oryza sativa L.). International Journal of Genetics, ISSN: 0975 - 2862 \& E-ISSN: 0975-9158, Volume 10, Issue 4, pp.-409-411. DOl: http://dx.doi.org/10.9735/0975-2862.10.4.409-411

Copyright: Copyright@2018 Srinivas B., et al., This is an open-access article distributed under the terms of the Creative Commons Attribution License, which permits unrestricted use, distribution and reproduction in any medium, provided the original author and source are credited.

\section{Introduction}

Rice is the main staple food and being used in regular diet in most of Asian countries. Achieving high yields in paddy depends upon the variable weather conditions, incidence of pest and diseases at critical stages of crop period and selection of the variety suitable for that particular area and season. As the saturation in yield levels are being regularly flouting due to changing climate conditions and evolution of new races or biotypes of major pests like BPH and gall midge, there is a need to develop the genotypes which could withstand these unfavourable conditions. Improving the yield is a complicated phenomenon as it is influenced by several other parameters. Finding the variability among the available germplasm for a particular character is the key source for improvement of concerned trait. Gall midge is becoming one of the major pests of rice influencing the yield to a considerable extent. In India, gall midge has been reported in almost all rice growing states. The loss in grain yield varies from 3to $70 \%$ in India [1] and gall midge has been reported from almost all the rice growing states except the Western Uttar Pradesh, Uttaranchal, Punjab, Haryana, hill states, Himachal Pradesh and Jammu and Kashmir [2]. Breeding for resistant lines is a continuous process to check the breakdown of resistance in existing popular varieties. The present study is aimed at the finding out the variability for various yield and quality parameters and identifying the gall midge tolerant genotypes to use further in breeding programmes to develop high yielding and gall midge tolerant varieties.

\section{Materials and Methods}

The present study was conducted with 45 rice genotypes at Regional Agricultural Research Station, Polasa, Jagtial during Kharif, 2014. Experiment was laid out in randomized block design replicated thrice with the spacing of $15 \times 15 \mathrm{~cm}$ with a plot size of $10.08 \mathrm{~m}^{2}$. Gall midge data was recorded as per the SES, IRRI [3]. Quantitative parameters viz., effective bearing tillers per plant, plant height, panicle length and numbers of grains per panicle were recorded at maturity on 10 random plants from each treatment in all three replications. Days to $50 \%$ flowering and yield were taken on whole plot basis, whereas, random sample from each entry of each replication after harvest was taken for recording the 1000 grain weight and quality characters viz., hulling percentage, milling percentage and head rice recovery. The mean data was subjected to analysis as per the Panse and Sukhathme [4] and genetic divergence was estimated as per the Mahalanobis [5] $D_{2}$ statistics. The genotypes were grouped into different clusters as per the Tocher's method by Rao [6] and cluster distances along with the cluster means also computed.

\section{Results and Discussion}

Analysis of variance [Table-1] revealed significant differences among all the genotypes for all the characters under the study indicating the presence of ample amount of diversity in the present experimental material. 45 rice genotypes were grouped into eight clusters [Table-2] based on their $D_{2}$ values following the Tocher's method. Highest number of genotypes was placed in the cluster III (17) followed by cluster IV (11), cluster I (8) and cluster V (5) whereas, single genotype was allotted to each cluster II, VI, VII and VIII. All the genotypes of present study belong to same geographical area grouped in different clusters which might be due to selection differential and or genetic drift under diverse environmental conditions within same geographical areas, Rajesh, et al., [7]. This indicated that distribution pattern of genotypes into clusters did not follow their origin of area. This clustering pattern is similar to the results obtained by Pathak, et al., [8] and Girish, et al., [9]. Inter and intra cluster distances are depicted in [Table-3] revealed that highest intra cluster distance values were observed in cluster $\mathrm{V}$ (7.32) followed by cluster IV (6.68), cluster I (6.09) and cluster III (5.85), whereas, zero intra cluster distance value was observed for the clusters II, VI, VII and VIII. This indicates the wide genetic variation among the genotypes included in the cluster $V$ and could give due importance while selecting the parents for hybridization programme and selection within this cluster may be done on the basis of highest mean for desirable traits Ramanjaneyulu, et al. [10]. The genotypes grouped in the same cluster are considered to be closely related than the genotypes grouped in different clusters. 
Table-1 Analysis of variance for yield and quality parameters in rice genotypes

\begin{tabular}{|c|c|c|c|c|c|c|c|c|c|c|c|c|}
\hline $\begin{array}{l}\text { Source of } \\
\text { variation }\end{array}$ & $\begin{array}{l}\text { Degrees } \\
\text { of } \\
\text { freedom }\end{array}$ & $\begin{array}{l}\text { Days to } \\
50 \% \\
\text { flowering }\end{array}$ & $\begin{array}{l}\text { Effective } \\
\text { bearing } \\
\text { tillers/plant }\end{array}$ & $\begin{array}{l}\text { Plant } \\
\text { height }\end{array}$ & $\begin{array}{l}\text { Panicle } \\
\text { length }\end{array}$ & $\begin{array}{l}1000 \\
\text { grain } \\
\text { weight }\end{array}$ & $\begin{array}{l}\text { Number of } \\
\text { grains/panicle }\end{array}$ & $\begin{array}{l}\text { Grain } \\
\text { yield }\end{array}$ & $\begin{array}{c}\text { Hulling } \\
\text { percentage }\end{array}$ & $\begin{array}{c}\text { Milling } \\
\text { percentage }\end{array}$ & $\begin{array}{l}\text { Head } \\
\text { rice } \\
\text { recovery }\end{array}$ & $\begin{array}{l}\text { Percent } \\
\text { of galls }\end{array}$ \\
\hline Replications & 2 & 3.21 & 0.14 & 9.13 & 0.39 & 1.02 & 866.81 & 0.46 & 0.68 & 1.37 & 0.31 & 0.36 \\
\hline Treatments & 44 & $127.62^{* *}$ & $4.99^{* \star}$ & $280.55^{\star \star}$ & $9.99^{* *}$ & $47.43^{* *}$ & $11482.37^{* *}$ & $1.32^{* *}$ & $33.18^{* *}$ & $27.69^{* *}$ & $77.90^{* *}$ & $26.12^{* \star}$ \\
\hline Error & 88 & 1.6 & 0.06 & 16.52 & 0.96 & 1 & 731.46 & 0.33 & 0.89 & 2.24 & 1.82 & 3.08 \\
\hline
\end{tabular}

Table-2 Distribution of 45 rice genotypes in different clusters

\begin{tabular}{|c|c|c|}
\hline $\begin{array}{c}\text { Cluster } \\
\text { No }\end{array}$ & $\begin{array}{c}\text { No. of } \\
\text { genotypes }\end{array}$ & Genotype \\
\hline 1 & 8 & JGL 23185, JGL 23829, JGL 23770, JGL 23666, JGL 23678, JGL 23655, JGL 21836, JGL 23832 \\
\hline 2 & 1 & JGL 21800 \\
\hline 3 & 17 & $\begin{array}{l}\text { JGL 18799, JGL 21075, JGL 21854, JGL 23795, JGL 20779, JGL 23634, JGL 3844, JGL 3828, JGL 3855, JGL 23714, JGL 18222, } \\
\text { JGL 23710, JGL 23853, JGL 23713, JGL 23183, JGL 18629, JGL 23640 }\end{array}$ \\
\hline 4 & 11 & JGL 23796, JGL 23825, JGL 23808, JGL 23800, JGL 23824, JGL 23848, JGL 23802, JGL 23816, JGL 18047, MTU 1010, JGL 23835 \\
\hline 5 & 5 & JGL 23709, JGL 23842, JGL 23746, JGL 17653, JGL 23647 \\
\hline 6 & 1 & MTU 1001 \\
\hline 7 & 1 & JGL 11727 \\
\hline 8 & 1 & JGL 11470 \\
\hline
\end{tabular}

Table-3 Average intra (diagonal) and inter cluster distances (Tocher method) for 45 rice genotypes

\begin{tabular}{|l|c|c|c|c|c|c|c|c|c|}
\hline Clusters & Cluster I & Cluster II & \multicolumn{1}{c|}{ Cluster III } & \multicolumn{1}{c|}{ Cluster IV } & Cluster V & Cluster VI & Cluster VII & \multicolumn{1}{c|}{ Cluster VIII } \\
\hline Cluster I & 6.09 & 6.78 & 9.29 & 9.39 & 8.32 & 10.95 & 10.39 & 15.05 \\
\hline Cluster II & & 0 & 8.84 & 6.65 & 8.6 & 12.33 & 11.95 & 15.91 \\
\hline Cluster III & & & 5.85 & 10.69 & 10.25 & 7.66 & 7.71 & 9.87 \\
\hline Cluster IV & & & & 6.68 & 10.31 & 12.31 & 13.53 & 17.59 \\
\hline Cluster V & & & & & 7.32 & 12.1 & 11.01 & 15.66 \\
\hline Cluster VI & & & & & & 0 & 8.12 & 9.1 \\
\hline Cluster VII & & & & & & & 0 & 8.93 \\
\hline Cluster VIII & & & & & & & & 0 \\
\hline
\end{tabular}

Table-4 Cluster means and percent contribution of 11 traits towards total divergence for 45 rice genotypes

\begin{tabular}{|c|c|c|c|c|c|c|c|c|c|c|c|}
\hline Cluster & $\begin{array}{c}\text { Days to } \\
50 \% \\
\text { flowering }\end{array}$ & $\begin{array}{l}\text { Effective } \\
\text { bearing } \\
\text { tillers/plant }\end{array}$ & $\begin{array}{c}\text { Plant } \\
\text { height } \\
\text { (cm) }\end{array}$ & $\begin{array}{c}\text { Panicle } \\
\text { length } \\
\text { (cm) }\end{array}$ & $\begin{array}{c}1000 \\
\text { grain } \\
\text { weight }(\mathrm{g})\end{array}$ & $\begin{array}{c}\text { Number of } \\
\text { grains / } \\
\text { panicle }\end{array}$ & $\begin{array}{l}\text { Grain } \\
\text { yield } \\
\text { (t/ha) }\end{array}$ & $\begin{array}{c}\text { Hulling } \\
\text { percentage } \\
(\%)\end{array}$ & $\begin{array}{c}\text { Milling } \\
\text { percentage } \\
(\%)\end{array}$ & $\begin{array}{l}\text { Head rice } \\
\text { recovery }\end{array}$ & $\begin{array}{c}\text { Percent } \\
\text { of galls } \\
(\%)\end{array}$ \\
\hline Cluster I & 90.63 & 7.55 & 104.45 & 24.56 & 20.85 & 186.46 & 8.51 & 79.11 & 67.58 & 51.01 & 1.8 \\
\hline Cluster II & 88 & 9.1 & 100.4 & 24.07 & 16.83 & 185.33 & 7.81 & 78.87 & 69.7 & 55.13 & 0 \\
\hline Cluster III & 101.24 & 7.64 & 115.38 & 25.4 & 15.81 & 252.18 & 8.51 & 80.53 & 69.84 & 59.38 & 1.26 \\
\hline Cluster IV & 92.18 & 9.95 & 99.55 & 25.38 & 21.83 & 144.52 & 8.75 & 78.89 & 67.33 & 58.33 & 2.05 \\
\hline Cluster V & 96.93 & 7.89 & 113.8 & 24.77 & 18.39 & 190.53 & 8.1 & 72.32 & 63.2 & 50.61 & 5.44 \\
\hline Cluster VI & 108 & 7.5 & 119.8 & 23.87 & 23.4 & 143.33 & 8.36 & 82.33 & 70.33 & 59.67 & 0.87 \\
\hline Cluster VII & 104 & 6.87 & 129.4 & 32.2 & 18.13 & 232.67 & 8.85 & 81.33 & 69.67 & 51.33 & 0.43 \\
\hline Cluster VIII & 114.67 & 6.73 & 117.27 & 24 & 12.67 & 308.33 & 7.13 & 84.33 & 67.67 & 55.33 & 0 \\
\hline $\begin{array}{l}\% \\
\text { Contribution } \\
\text { of character }\end{array}$ & 25.76 & 27.27 & 0.51 & 2.12 & 13.33 & 0.2 & 0 & 13.33 & 3.74 & 10.91 & 2.83 \\
\hline $\begin{array}{l}\text { Number of } \\
\text { times } \\
\text { ranked first }\end{array}$ & 255 & 270 & 5 & 21 & 132 & 2 & 0 & 132 & 37 & 108 & 28 \\
\hline
\end{tabular}

Therefore, crossing between the genotypes belongs to the same cluster may not results in achieving the better recombinants. These findings are similar to the results obtained by the Ahmed, et al. [11], Apsath Beevi and Venkatesan [12] and Supriya, et al. [13]. Highest inter cluster distance was observed between cluster IV and VIII (17.59) followed by II and VIII (15.91), V and VIII (15.66), I and VIII (15.05), IV and VII (13.53) and II and VI (12.33), whereas, least inter cluster distance was observed between clusters II and VI (6.65) followed by I and II (6.78). To obtain good segregants, it is always advisable to select parents for hybridization programme from the clusters having highest inter cluster distance than choosing the parents from the clusters having low inter cluster distance between them. These results are similar to the findings of Banumathy, et al. [14]. Variation present in the cluster means [Table-4] for different traits is also a key factor in choosing the parents for hybridization from different clusters for improvement of characters. Clusters I, II and IV exhibited lowest means for days to $50 \%$ flowering and hence genotypes from these clusters could be selected for crossing programme for obtaining the early maturing recombinants, whereas use of JGL 11470 (cluster VIII) as a parent could results in obtaining medium to long duration segregants. For obtaining populations with good number of productive tillers, more emphasis should be given to the genotypes from clusters $\|$ and IV as parents. To develop semi dwarf rice varieties which can resist lodging, genotypes from clusters II and IV could be chosen for hybridization as they recorded lowest means for plant height. From the present experimental material, the trait number of grains per panicle, one of the important yield contributing characters, could be improved by crossing the genotypes of clusters III and VIII with JGL 11727 (cluster VII) as it recorded best value for the panicle length. Also, the present experimental material provides a good scope for the breeders to develop the varieties with coarse or fine grain type. Genotypes from clusters II, III and VIII could be the good source for developing the fine grain cultures, whereas, genotypes from I, IV and VI may produce course grain recombinants in segregating populations. Similarly, genotypes from clusters III, IV and VI may yield segregants with good head rice recovery. Segregating populations with gall midge resistance could be produced by using JGL 21800 (cluster II) and JGL 11470 (cluster VIII) as parents in 
breeding programmes, whereas, genotypes from clusters VI and VII also could be a better choice for breeders in developing gall midge resistant lines. These research findings are similar to the results obtained by Srinivas, et al., [15] and Mohan, et al., [16]. Based on the percent contribution of each character [Table-4] towards total genetic divergence, effective bearing tillers per plant which is an important yield contributing trait exhibited maximum divergence $(27.2 \%)$ in the present experimental material followed by days to $50 \%$ flowering $(25.76 \%)$ and 1000 grain weight (13.33\%). The quality parameter, hulling percent (13.33\%) and head rice recovery $(10.91 \%)$ also contributed a considerable amount to the total of genetic divergence in the present material. Yield, being a complex trait and depends on various yield contributing and morphological characters exhibited zero contribution towards total divergence, whereas, other traits viz., plant height $(0.51 \%)$, number of grains per panicle $(0.2 \%)$, milling percent $(3.74 \%)$ and gall midge incidence $(2.83 \%)$ exhibited least percent contribution to the divergence. Similar results were reported by Ramanjaneyulu, et al., [10], Ramesh Babu and Sreelakshmi [17] and Supriya, et al., [13]. Hence, there is a less scope for improvement of the traits showing least contribution towards divergence in desirable direction from the present experimental and due importance could be given to the traits viz., effective bearing tillers per plant, days to $50 \%$ flowering, 1000 grain weight and hulling percent while using the present material in the breeding programme.

Summary: Development of desirable segregants could be achieved by making crosses between the genotypes of cluster IV and cluster VIII and the cultures JGL 21800 and JGL 11470 are identified as good sources for breeding of new rice varieties with gall midge resistance.

Application of Research: Identifying good rice recombinants with high yield coupled with gall midge resistance.

Research category: Crop improvement through genetic analysis in rice

Abbreviations: \%: percent, m: meter, cm: centimeter, viz.,: videlicet, et al.,: et elia, t: tones, ha: hectare, HRR: head rice recovery, SES: standard evaluation system, IRRI: International Rice Research Institute

Acknowledgment/Funding: Author thankful to Rice Research Scheme, Regional Agricultural Research Station, Professor Jayashankar Telangana State Agricultural University, Polasa, Jagtial, Telangana, 505529

\section{*Chairperson of research: Dr B. Srinivas}

University: Professor Jayashankar Telangana State Agricultural University

Research project name: Development of high yielding rice varieties having resistance to Gall midge in medium \& short duration group

\section{Author Contributions: All author equally contributed}

Author statement: All authors read, reviewed, agree and approved the final manuscript

\section{Conflict of Interest: None declared}

Ethical approval: This article does not contain any studies with human participants or animals performed by any of the authors.

\section{References}

[1] Chatteri S.M., Kulshreshtha J.P., Rajamani S. and Prakash Rao P.S. (1976) Pest. Inform, 2, 33-36.

[2] Bentur J.S., Pasalu I.C., Sharma N.P., Prasad Rao U. and Mishra B. (2003) Res. Paper Series, Directorate of Rice Research, 20.

[3] IRRI (2002) Standard Evaluation System for Rice, International Rice Research Institute, Los Baños, Philippine.

[4] Panse V.G. and Sukhathme P.V. (1985) Statistical methods for agricultural workers, Indian Council of Agricultural Research, New Delhi.

[5] Mahalanobis P.C. (1936) Proceedings of the National Institute of Sciences of India, 2, 49-55.

[6] Rao C.R. (1952) Advance Statistical Methods in Biometrical Research. John Wiley and Sons, New York.

[7] Rajesh T., Paramasivam K. and Thirumeni S. (2010) Electronic Journal of Plant Breeding, 1(2), 199-204

[8] Pathak R., Singh M. and Henry A. (2009) Indian J. Agric. Sci, 79(7), 559-561.

[9] Girish M.H., Gasti V.D., Thammaiah N., Kerutagi M.G., Mulge R., Shantappa T. and Mastiholi A. B. (2012) Karnataka J. Agric. Sci, 25 (2), 245-247.

[10] Ramanjaneyulu A.V., Gouri Shankar V., Neelima T.L. and Shashibhushan D. (2014) SABRAO Journal of Breeding and Genetics, 46(1), 99-111.

[11] Ahmed A., Shaon S.G., Islam M.S., Saha P.S. and Islam M.M. (2014) Bangladesh J. PI. Breed. Genet, 27(2), 25-32

[12] ApsathBeevi H. and Venkatesan M. (2015) Journal of the Andaman Science Association, 20(1), 35-38

[13] Supriya, Jaiswal H.K. and Anurag Srivastva (2017) International Journal of Pure and Applied Bioscience,5 (2),441-448

[14] Banumathy S., Manimaran R., Sheeba A., Manivannan N., Ramya B., Kumar D. and Ramasubramanian G.V. (2010) Electronic Journal of PlantBreeding, 1(4), 500-504.

[15] Srinivas B., Chandramohan Y., Thippeswamy S. and Padmaja D. (2016) International Journal of Bio-resource and Stress Management, 7(1), 001-007.

[16] Mohan Y.C., Thippeswamy S., Bhoomeshwar K., Madhavilatha B. and Jameema Samreen (2015) SABRAO Journal of Breeding and Genetics, 47(2), 160-171.

[17] Ramesh Babu P. and Sreelakshmi Ch. (2017) Journal of Rice Research, (1), 17-20. 